\title{
Observaciones sobre Radiopelvimetría
}

Trabajo presentado a la Primera Convención Nacional de Obstetricia y irinecologia por los doctores:

Gonzalo Esguerra Gómez

Alberto Cárdenas Escovar ${ }^{\circ}$

Ramon González García +

\section{Clínica David Restrepo. - Bogotá.}

Aunque la radiopelvimetría no es un método igualmente difundido en todos los centros hospitalarios, debido principalmente a la diversidad de escuefas obstetricas y a las posibilidades materiales de dotación, se reconocen hoy en todas partes indicaciones concretas, en las cuales los Rayos X aportan al obstetra utilidad innegable. Queremos dejar establecido, de una vez. el principio aplicable al estudio radiologico como a todo procedimiento de laboratorio: estas investigaciones suministran datos que son, solamente, una parte de los factores necesarios al clínico para el establecimiento de un diagnóstico, un pronostico ! ma linea de conducta. Por lo que hace al problema obstétrico, es evidente que ins deducciones relativas al pronóstico del parto obtenidas del estudio radiolosico. no pueden tomar en cuenta el importante factor de la dinamica uterina. como tampoco la capacidad de la cabeza fetal para amoldarse a la forma y tamaño del conducto pélvico. Así pues, es obvio que el juicio del obstetra no puede basarse sobre apreciaciones unilaterales, sino que debe ser el resultado de una integración de los varios elementos suministrados por todos los procedimientos de examen. Entre estos la radiopelvimetría ha llegado a constituir un importante método de exploración de las relaciones céfalo-pélvicas. 
La radiopelvimetría puede definirse como un conjunto de métodos radiológicos cuyo objeto es medir con la mayor precisión posible los diámetros de los diversos planos de la pelvis ósea, $y$, en ciertas condiciones, los diámetros de la cabeza fetal.

Como estas medidas van a efectuarse sobre una imagen que ha sufrido determinada distorsión con respecto a las magnitudes reales del objeto radiografia do, el primer problema técnico que debe resolver el radiólogo es la corrección de dicha distorsión por medio de artificios, o de cálculos matemáticos, que le permitan obtener cifras aproximadas lo más posible a las medidas reales del objeto. Esto constituye el aspecto cuantitativo de la avaluación radiológica de la pelvis. La apreciación cualitativa es simplemente el estudio de la morfología 0 arquitectura de la misma y constituve un aspecto no menos importante que el primero, en el pronóstico de los problemas mecánicos del parto.

Para corregir la distorsión se han ofrecido varias soluciones, que pueden ser clasificadas en tres grupos:

a) Métodos Isométricos. Son aquellos en los cuales se imprimen sobre la película, sea por exposición simultanea, o por doble exposicion, un objetc opaco con marcas espaciadas a centímetro. Dicho objeto debe ser colocado a la misma altura sobre la película que el diámetro que se desea medir. de modo que la distorsión sea la misma. Entonces las medidas podran ser tomadas directa mente sobre la imagen de la escala opaca. Esta es la base del método de Wietzner que permite medir los diámetros sagitales en la placa lateral. colocando una ro gla opaca verticalmente en el pliegue interglúteo; tambien es la base del métod posterior, mediante una lámina de plomo con perforaciones espaciadas metro, que se coloca paralelamente a la película a la misma altura del estrech superior, y se imprime sobre la misma película en una segunda exposición ur vez que la paciente se ha retirado de la mesa; otros ejemplos de metodos isom tricos son los de Robins y Colcher-Sussman, quienes emplean reglas opacas a altura del gran trocanter y de los isquiones, respectivamente. para medir los di metros transversos de los estrechos medio e inferior.

b) Métodos Matemáticos. En estos se busea la medida real por una si ple proporción, en la cual se conocen tres valores de triangulos semejantes: medida del diámetro estudiado sobre la imagen; la distancia tubo película, y distancia tubo objeto (o sea la distancia entre el tubo y el plano del diámetro o se estudia). Es evidente que por simple cálculo aritmético se puede despejar cuarto valor, que es la medida real o corregida. Este metodo se simplifica si construyen tablas, gráficos o reglas de corredera, para evitar las operaciones méticas. Esto constituve la base del método de Pfahler. introducido en 1906 de los métodos más modernos de Snow y del Parallax. En el de Snow se uti como "factor de corrección" la distancia objeto película. El Parallax utiliza e siciones sucesivas sobre dos placas diferentes y con cambio de posición del sobre el plano horizontal para modificar el ángulo de incidencia de los rayos, relación a la pelvis ósea y a una regla con dos marcas opacas de distancia $c$ 
cida; el estudio se hace sobre las dos películas superpuestas de acuerdo con señales previamente colocadas sobre el chasis, y aunque el cálculo se basa sobre la misma proporción aritmética, su desarrollo es más complicado y lleva a tres fórmulas finales que son las usadas para la determinación de las medidas; este método parece ser de los más exactos, pues tiende a eliminar ciertos-errores personales en la técnica.

c) Métodos Estereoscópicos. Son aquellos en los cuales los diámetros pélvicos se miden en el espacio, bajo visión estereoscópica, lo cual permite estudiar la imagen en su relación verdadera con el objeto original, es decir, libre de toda distorsión.

Es oportuno decir, antes de seguir adelante, que la mayoría de los métodos radiopelvimétricos son buenos, pero que la utilidad práctica de determinado procedimiento depende de su simplicidad, de su precisión, y, principalmente, de la experiencia que el investigador hava alcanzado con ese mismo método. En otras palabras, en radiopelvimetria, como en muchos otros trabajos experimentales, dos métodos distintos que persiguen un mismo objeto pueden ser igualmente buenos si las personas que los utilizan han alcanzado una práctica suficiente con ellos, y una cooperacion satisfactoria con los clínicos que van a servirse de esos exámenes para atención de sus pacientes. De manera que en un rospital cualquiera los resultados deben ser razonablemente buenos si se elige un métudo práctico y se trabaja con él durante un tiempo suficientemente largo para dominarlo y para lograr uniformidad de criterio, en armonía con el personal obstétrico. Este interesante aspecto de la investigación ha recibido plena confirmación en el curso de nuestra experiencia en las Clínicas de Marly y David Restrepo, como veremos mas adelante.

\section{Desarrollo de nuestra experiencia con la Radiopelvimetría}

Interesados en la utilidad que podría aportar la radiopelvimetría a la soluicin de ciertos problemas obstétricos. comenzamos a aplicarla en la Clínica de larly en el año de 19+8, en una serie de casos en los cuales encontrabámos indicaciones que justificaban esa investigacion. Las indicaciones para el empleo del metodo se ajustaron desde el principio a las establecidas por Meave Kenny, de la Escuela Médica de Post-graduados, Universidad de Londres, en su estudio sobre radiopelvimetría publicado en 1945 . (1) Dichas indicaciones pueden resumirse así:

la-Estrechez pélvica evidente, hallada en el examen clínico.

2a-Desproporción céfalo-pélvica, sospechada por falta de encajamiento en primigrávidas a término.

3 -Malas presentaciones, inclusive pelvis persistente en primigrávidas.

4a-Evidencia clínica, o historia de enfermedades óseas de la pelvis, la columna, o las articulaciones coxo-femorales. 
5 - Antecedente de partos prolongados u operatorios, especialmente si dieron por resultado niños nacidos muertos, o muertes neo-natales, o lesiones graves de la madre o del niño.

Desde el comienzo que ruvo como norma practicar la exploración radiológica lo más cerca posible del termino del embarazo, generalmente dentro de las dos últimas semanas, con el objeto de obtener una información más completa sobre las relaciones céfalopélvicas finales, y, a ser posible, sobre el volumen de la cabeza fetal. Sin embargo, nuestro interés se concentró sobre las medidas pélvicas, y no atribuimos mavor valor a la cefalometría fetal, teniendo en cuenta la imposibilidad de estimar correctamente la relación de altura de la cabeza del leto con la película, excepto en los casos en que aquella se encuentra encajada, Y por consiguiente los metodos isométricos (Weitzner) y matemáticos (Snow) pueden dar una aproximacion aceptable en la medida de los diámetros cefálicos fetales.

Los métodos empleados han sido isométricos (Weitzner, Thoms, Robins, Colcher-Sussman) y matemáticos (Snow y Parallax) (2). El Parallax (3) es una adición más reciente en nuestra experiencia, pues solamente comenzamos a usarlo en 1952.

Los resultados iniciales fueron desconcertantes por las diferencias numéricas muy notorias en las medidas obtenidas para un mismo diámetro por métodos distintos, diferencias que nos hacian pensar en la invalidez de todos los métodos y en la inutilidad de tratar de aportar aquellas medidas a la solución de un problema clinico. Sin embargo, después de una aplicación continuada de los métodos arriba mencionados. a lo largo de un año de experiencia con todos ellos y en manos del mismo investigador se ha llegado a obtener una concordancia mur satisfactoria entre las citras suministradas por todos los métodos, hasta el punto de que las diferencias se han reducido a unos pocos milimetros y en muchas lecturas las citras son identicas, sea cual fuere el método empleado. Ćreemos que este progreso se debe a la creciente experiencia del radiólogo en la correcta aplicacion tecrica de todos los métodos radiopelvimétricos, y principalmente en la buena lectura de las imágenes, es decir en la determinación más precisa de los puntos de reparo que en la imagen radiológica limitan los diversos diámetros de la pelvis usea. La determinación de estos puntos es función no solamente de la nitidez de las imágenes obtenidas por el empleo de una técnica óptima. sino tambien de la uniformidad de criterio anatomo-radiológico en el reconocimiento de los puntos ( ${ }^{+}$).

El informe radiologico que estamos usando incluve los siguientes aspectos:

Datos generales relativos al feto.

Estudio cualitativo de la pelvis (morfología pélvica), y su clasificación de acuerdo con los cuatro tipos establecidos por Caldwell y Moloy (Pitecoide o antropoide. Ginecoide. Androide. Platipeloide), sobre la base del indice pélvico de Turner (").

Estudio cuantitativo de la pelvis (Pelvimetría), que comprende los datos numéricos de las medidas de los diámetros de los estrechos superior, medio e inferior, y de la amplitud del ángulo subpúbico. El informe suministra todos 
los valores numéricos, en centímetros y fracciones, obtenidos por los primitivos métodos isométricos, por el método de Snow, y por el Parallax. Los diámetros medidos son los siguientes: Para el estrecho superior, el anteroposterior (promontoretropúbico) y el transverso máximo. Para el estrecho medio, el mediosacro-subpúbico y el inter-espinoso. Para el estrecho inferior el sagital posterior y el intertuberositario. Cada diámetro es clasificado en una de tres categorias (pequeño, mediano o grande) de acuerdo con la clasificación dada por Snow ("), y recientemente modificada por nosotros de acuer do con los promedios obtenidos en nuestras series.

Correcta Interpretación Clínica. Para que la lectura del informe radiopelvimétrico sea de alguna utilidad al clínico, se requiere que éste desarrolle su propia experiencia sobre el valor que puede darse a determinadas medidas de la pelvis. Lo ideal sería que todo obstetra hiciera una sintesis basándose en los siguientes elementos primordiales: Edad de la paciente. Paridad. Antecedentes obstétricos. Estado general. Edad del embarazo. Volumen del feto (estimado por palpación y por la altura uterina). Tipo de presentación. Apreciación clínica de la pelvis (pelvimetría interna por tacto vaginal: la pelvimetría externa tiene un valor muy relativo, excepto en casos de medidas extremas) y de las relaciones céfalo-pélvicas (palpación mensuradora). Solamente después de recoger todos esos datos, que desde luego constituyen la rutina de un buen examen obstétrico, y completados con los datos de la radiopelvimetría, el obstetra dispondría de información más o menos aproximada que le ha de permitir elaborar un pronostico sobre los fenómenos mecánicos del trabajo. Efectuar este proceso mental en todos los casos, con las imágenes radiológicas a la vista, y luégo escribir en la historia una apreciación pronóstica para compararla después con el resultado final del caso. es la única manera de formar el criterio obstétrico, y de aprender a dar el valor que corresponde a cada uno de los elementos clínicos. Siendo la radiopelvimetria uno de estos elementos, es claro que solamente después de haber aplicado a mu. chos casos el razonamiento descrito, los datos radiológicos, cualitativos y cuantitativos, comenzarán a tener algún valor para el clínico, y alguna utilidad para la orientación de la conducta obstétrica en los casos en que se teme un problema mecánico.

\section{Estudio de algunas Historias Clínicas}

En este trabajo hemos analizado una serie de 46 historias clinicas, con radio. pelvimetrías realizadas en la Clínica David Restrepo, desde el mes de junio de 1952 hasta el presente. Las indicaciones para el estudio radiologico en estas pacientes han sido las enumeradas arriba. El estudio de estos casos demuestra que cllos pueden distribuirse en dos grupos, a saber:

Primer grupo: Aquellos casos en que hubo CONCORDANCIA entre el pronóstico obstétrico, parcialmente basado sobre el estudio radiologico, y el resultado final del caso, es decir, en que la evolución ulterior comprobó lás apreviaciones hechas con base en la radiopelvimetria y teniendo en cuenta los demás uctores clínicos (ver arriba). Este grupo comprende treinta y siete casos $s 0,+\%)$, del número total de observaciones, y puede distribuirse de la manera siguiente:

Partos espontáneos, normales, 25 (67,5\% del grupo de concordancias). En estos casos, a pesar de existir dudas sobre la posibilidad del parto por vías natu- 
rales, el estudio radiológico permitió formular un pronóstico de parto espon táneo con mecanismo normal, lo cual se cumplió sin dificultades.

Forceps (en estrechos medio e inferior, pero no los forceps de indicación profiláctica en el desprendimiento), $6(16,2 \%)$. Este subgrupo incluye aplicaciones de forceps que fueron indicadas por dificultades mecánicas (rotación descenso y desprendimiento), que habian sido previstas al estudiar radiológicamente las caracteristicas de la pelis en cuestión. La radiopelvimetría es particularmente útil en estos casos, pues permite prever no solamente la dificultad mecánica que habra de presentarse, sino también las modalidades de técnica en la aplicación de forceps que hará más fácil y menos traumatizante la interven ción para salvar la distocia. Los defectos de rotación de vertices en variedad posterior, en pelvis de tipo Pitecoide, con detenimiento en el estrecho medio, son un buen cjemplo, quizás el más importante, de este grupo.

Cesáreas, 5 (13.5\% del grupo de Concordancia). En estas cesáreas el estudio radiopelvimétrico confirmó las sospechas de desproporcion céfalo-pélvica, la cual fue ulteriormente comprobada mediante la prueba del trabajo. Aunque nues tra serie no incluye ningun caso de cesárea electiva por deficiencia de los planos medio e inferior. queremos mencionar las pelvis androides. en cuvo diagnóstico los Ravos $\mathrm{X}$ son invaluables. Es sabido que una pelris de este tipo puede dar distocias de grave riesgo, por detenimiento en los planos inferiores de la pel. vis, después de una prueba de trabajo más o menos prolongada mediante la cual se ha logrado salvar el plano del estrecho superior. viendose entrentado el obstetra inexperto a una situación engañosa, que determina en una cesárea tardía, o en una aplicación desastrosa de forceps. Estos son los casos por fortu na cada vez menos frezuentes, en que el llamado especialista realiza su proez: al extraer un feto muerto o moribundo con graves lesiones matemas. despué de emplear fuerzas atléticas en la tracción sobre el mortifero instrumento.

Partos espontáneos después de inducción medica: $1(2,-7)$. Esta obser vacion corresponde a una paciente con pelvis limite de tipo Ginecoide. que cum plio el témino. tanto cronológicamente como por altura uterina, en la cual se decidió evitar el problema de la desproporcion cétalo-pelrica induciéndola mé dicamente.

Segundo grupo: Aquellos casos en que hubo DISCORD.ANCIA entre e pronóstico de mecanismo y la evolución ulterior del caso. Comprende nueve ob servaciones, es decir $19,5 \%$ del número total. Tiene los siguientes subgrupos

Partos espontáneos normales. 2 (22.2\% del grupo de discordancia), es decir casos en que no se produjeron las distocias mecanicas que se esperaban.

Forceps. $3(33,3 \%$ del grupo de discordancia). No obstante las aplicacione impuestas por dificultades mecanicas fueron solamente dos, pues el tercer for ceps estuvo indicado por una emergencia imprevisible y no relacionada en est caso con factores pélvicos (prolapso del cordon).

Cesáreas, 4 (4t.4\% del grupo de discordancia), o sea casos en que el es tudio radiologico no hacía prever distocia, $y$ sin embargo en el curso del traba 
jo surgió la indicación de cesárea por falta de encajamiento que no pudo ser más tarde explicado por causa distinta de desproporción céfalo-pélvica.

\section{Muertes Neonatales}

En el primer grupo hubo una muerte del recién nacido, que se produjo a las veinticuatro horas de un parto espontáneo. El trabajo había sido de once horas de duración, en una secundigestante con antecedentes de cesárea (se des conoce la indicación anterior). En el caso actual no hubo factor alguno de suIrimiento obstétrico que explicara la muerte neonatal, que parece haber sido debida a atelectasia pulmonar.

\section{Cesáreas}

El estudio del grupo de cesáreas suministra datos interesantes. Vemos, en primer lugar, que en la serie de concordancias, las cesáreas están representadas por un $13,5 \%$ (con relación al total del mismo grupo), al paso que en las discordancias, las cesureas son un $44,4 \%$. Esto quiere decir, que después del estudio radiológico. fueron menos las cesáreas hechas de acuerdo con pronóstico, que las cesáreas realizadas a pesar de que el estudio radiológico no paecía indicar su necesidad. En otras palabras, si hubo error en el pronóstico diológico, fue en el sentido conservador, indicando el parto por vías naturales, ye resulió irrealizable ulteriormente, y no en el sentido intervencionista, que veria el de indicar cesáreas no justificadas por las condiciones reales. Esta última contingencia sería censurable, pues significaría que el factor radiológico estaría influenciando la conducta obstetrica en el sentido de elevar el número de cesáreas injustificables. Y vemos que no es esto lo ocurrido dentro de la serie estudiada, sino que, por el contrario. el numero de intervenciones indicadas por la evolución ulterior del caso fue mavor de lo que el estudio radiológico hacía prever, lo cual no afecta en manera alguna el buen criterio de la conducta obstétrica puesto que la prueba de trabajo bien conducida es amplio margen de seguridad ue permite decidir oportunamente una cesárea, a pesar de que inicialmente no pareciera estar indicada.

En apoyo de esta misma observación están los datos obtenidos al analizar las historias de pacientes multigestantes con antecedentes de cesáreas practicadas en otros hospitales. Encontramos en la serie 9 observaciones de pacientes que habian sido sometidas a cesareas anteriormente. En cinco de ellas la información que se pudo obtener sobre la indicación de la intervención sugiere la distocia por desproporcion céfalo-pelvica. En seis, de las nueve, el estudio radiológico no mostró la necesidad de repetir la cesárea, y todas las seis, en efecto, tuvieron parto por vías naturales. De las tres restantes, dos tuvieron nueva esárea por indicación clinica y radiológica. Solamente en una la intervención iue eventualmente necesaria a pesar de que los datos radiológicos parecían indicar la posibilidad del parto por vías naturales. 


\section{CONCLUSIONES}

Este trabajo comprende una serie de 46 observaciones obstétricas en qui se practicó la radiopelvimetría por métodos isométricos y aritméticos o matemá ticos, en la Clínica de Maternidad David Restrepo de Bogotá.

Las diferencias numéricas en las medidas de los mismos diámetros obte nidas por métodos distintos, inicialmente muy notorias, han sido reducidas a ur minimo gracias a la experiencia progresivamente adquirida por un mismo in vestigador, lo cual da por resultado una aplicación más correcta y precisa de la técnicas elegidas.

En todos los casos se ha formulado un pronóstico obstétrico basado en lo factores clínicos y el factor radiológico. Ese pronóstico se ha comparado con 1 evolución ulterior de los casos.

Las observaciones, criticadas de esta manera, pueden clasificarse en do grupos: $80.4 \%$ de los casos mostraron concordancia entre el pronóstico y la evo lucion final. $19,5 \%$ mostraron discordancia.

Estas cifras pueden aceptarse como indices del valor pronóstico de la radir pelvimetria en la serie estudiada.

La radiopelvimetría es un auxiliar importante en la orientación de la con ducta obstétrica, y su utilidad es susceptible de acrecentarse mediante una but na cooperacion entre el clínico y el radiólogo, y a medida que tanto el uno com el otro desarrollan su experiencia y su criterio mediante la observacion de mu chos casos.

\section{R E F E R E N C I A S :}

1. - "The clinically suspect pelvis and its radiological investigation in 1.000 cases By Meave Kenny, of the Department of Obstetrics and Gynecology, Britis Postgraduate Medical School. Journal of Obstetrics and Gynecology of th: British Empire. Vol. 51. No 4, p. 277.

2.- "Algunas consideraciones sobre el empleo de los Rayos X en obstetricia", po Alberto Cárdenas Escobar. Bogotá. Revista de la Clínica de Marly, Vol. 1 Nos: $5,6,7$ y 8, p. 17.

3.-International Abstracts of Surgery, Vol. 70. p. 421. 1940.

4.-."Clinical Roentgenology of Pregnancy", William Snow, New York, 1942. 